\title{
AVALIAÇÃO SENSORIAL E RENDIMENTO DE FILÉS DEFUMADOS DE TILÁPIA (Oreochromis niloticus Linnaeus, 1757) NA PRESENÇA DE ALECRIM (Rosmarinus officinalis)
}

\author{
Sensory evaluation and yield of Tilapia (oreochromis niloticus) smoked fillets in rosemary \\ (Rosmarinus officinalis) presence
}

\author{
Lilian Dena dos Santos ${ }^{1}$, Ricardo Fiori Zara ${ }^{2}$, Jesuí Vergílio Visentainer ${ }^{3}$, \\ Makoto Matsushita ${ }^{3}$, Nilson Evelázio de Souza ${ }^{3}$, Maria Luiza Rodrigues de Souza Franco ${ }^{4}$
}

\begin{abstract}
RESUMO
Objetivou-se com este trabalho avaliar o efeito das formas de processamento e do alecrim na defumação dos troncos e filés sem pele de tilápia do Nilo sobre o rendimento e as características organolépticas. Independente da forma de processamento aplicada, os filés defumados na presença do alecrim apresentaram menor rendimento. Foi também observado que os filés obtidos a partir dos troncos defumados proporcionaram maiores rendimentos. Analisando a forma de processamento dos filés defumados, os provadores apresentaram maior aceitação para filés (FIL) $(2,88)$ em relação aos filés a partir dos troncos defumados (FTD) $(2,63)$. A presença de alecrim nos filés, independente da forma de obtenção do produto final, não foi significativo para aparência, cor, aroma e aceitação geral, em que as notas transformadas variaram de 2,70 a 2,77. Em relação às análises organolépticas das porções do defumado, a preferência foi maior para o consumo dos FIL em relação aos FTD. Os provadores não notaram diferenças quanto ao acréscimo de alecrim aos FIL e FTD, exceto para teor de sal.
\end{abstract}

Termos para indexação: Tilápia, defumação, análise sensorial, rendimento.

\begin{abstract}
The object of this study was to evaluate the rosemary effect on smoking of skin-less torso and fillets of Nile tilapia on yield and organoleptic characteristics. Independent of processing form applied, the smoked fillets in the rosemary presence presented smaller yield. It was also observed in the fillets from smoked torso than presented greater yield. With regard the processing forms of smoked fillets, the tasters had presented greater acceptance to fillets (FIL) (2.88) compared to fillets from smoked torso (FST) (2.63). The presence of rosemary on fillet independent of attainment form of final product was not significative to appearance, color, aroma and general acceptance, where the marks transformed was rather between 2.70 to 2.77 . With regards to organoleptic analyses of smoked fillets portions, the preference was better to FIL compared to FST. The tasters had not noticed significative differences with rosemary addition to FIL and FST, except to salt rate.
\end{abstract}

Index terms: Tilapia, smoking, sensory evaluation, yield.

\section{(Recebido em 23 de março de 2005 e aprovado em 14 de julho de 2006)}

\section{INTRODUÇÃO}

A tilápia é uma das espécies de peixes mais indicadas para a criação intensiva, por ser considerada de grande importância para a aquicultura mundial. A espécie apresenta requisitos típicos preferidos pelo mercado consumidor, tais como carne branca de textura firme, sabor delicado, de fácil filetagem, ausência de espinhas em "Y", além das características produtivas desejáveis para a criação: alta taxa de crescimento, adaptabilidade em diversas condições e criação, que colocam a tilápia entre as principais espécies comerciais (JORY et al., 2000).
O consumo de peixes ainda é baixo no Brasil, entre as formas de estimular o consumo de pescado busca-se a utilização de produtos elaborados e com melhores formas de apresentação, visto que o consumidor exige alimentos de preparo rápido e fácil. A defumação do pescado é um método tradicional e tem como finalidade proporcionar ao produto características organolépticas desejáveis, como cor, aroma, sabor e textura. Quando realizada de maneira convencional tem o intuito estender a vida útil do produto, devido aos efeitos combinados da salga, cocção, secagem e deposição de substâncias químicas bactericidas presentes na fumaça, como fenóis, aldeídos e ácidos orgânicos (SOUZA, 2003).

\footnotetext{
Zootecnista, doutoranda pelo Programa de Pós-graduação em Zootecnia - Universidade Estadual de Maringá - Av. Colombo 5790 - Campus Universitário Maringá - 87.020-900 - Maringá, PR.

Químico, doutoranda pelo Programa de Pós-graduação em Química - Universidade Estadual de Maringá - Av. Colombo 5790 - Campus Universitário Maringá - 87.020-900 - Maringá, PR.

${ }^{3}$ Professor Dr. do Departamento de Química - Universidade Estadual de Maringá - Av. Colombo 5790 - Campus Universitário Maringá - $87.020-900$ Maringá, PR.

${ }^{4}$ Professora Dra. do Departamento de Zootecnia - Universidade Estadual de Maringá- Av. Colombo 5790 - Campus Universitário Maringá - $87.020-900$ Maringá, PR - mlrsouza@uem.br
} 
A preocupação constante de proporcionar aos consumidores produtos de alta qualidade levou a adoção de medidas que permitam reduzir a oxidação durante as fases de processamento e armazenamento dos produtos. Shahidi \& Wanasundara (1992) consideram a adição de compostos antioxidantes uma das práticas mais importantes, devido ao baixo custo de obtenção, facilidade de emprego, eficácia, termo-resistência, neutralidade organoléptica e ausência reconhecida de toxidade, facilitando a sua seleção e utilização a nível industrial.

Dentre os antioxidantes, os de maior interesse são as substâncias naturais, incluindo as especiarias e seus extratos, os quais apresentam componentes com atividade antioxidante; deste fato decorre a aplicabilidade destas em diferentes preparações culinárias para intensificar a características organolépticas, aumentar a aceitabilidade e principalmente, melhorar a estabilidade oxidativa (MADSEN et al., 1996). Esses autores relatam que, componentes responsáveis pela estabilidade oxidativa têm sido identificados em várias especiarias, tais como, o alecrim, sálvia, tomilho, cravo-da-índia, dentre outras. A atividade antioxidante destas especiarias é atribuída principalmente devido à existência de compostos fenólicos. Dentre as especiarias, o alecrim (Rosmarinus officinalis) tem sido objeto de vários estudos e apresenta características organolépticas desejadas pelo o consumidor. É classificado pelo Council of Europe (1981) como um aromatizante natural, podendo ser adicionado aos alimentos.

Objetivou-se com este trabalho avaliar o efeito do alecrim na defumação de troncos e filés de tilápias do Nilo sobre as características organolépticas (aparência, aroma, cor, sabor, textura, teor de sal e aceitação geral) e rendimento no processo de defumação.

\section{MATERIAL E MÉTODOS}

\section{Amostragem}

Foram utilizados 85 exemplares de tilápia do Nilo (Oreochromis niloticus Linnaeus, 1757), capturados de tanques instalados na Aquabel (Rolândia), insensibilizadas com choque térmico (caixas isotérmicas com gelo moído e água, 1:1). As tilápias apresentaram peso e comprimento médio de $1,02 \pm 0,19 \mathrm{~kg}$ e $35,01 \pm 2,31 \mathrm{~cm}$, respectivamente.

\section{Procedimento experimental}

Os peixes foram separados em dois lotes de quarenta peixes e defumados: lote 1 - troncos limpos [peixe decapitado, eviscerado, sem escamas, sem nadadeiras e sem pele] ( 20 com alecrim e 20 sem alecrim) e lote 2 - filés (40 com alecrim e 40 sem alecrim), sendo que cada peixe do lote 2 forneceu um filé a ser defumado com alecrim e o outro sem alecrim. Os troncos e os filés limpos foram pesados (antes e depois da defumação) e identificados individualmente com uma placa metálica. Os filés referentes a cinco peixes foram destinados às análises na forma in natura (testemunha).

Os troncos e filés foram imersos em uma solução de salmoura a 20\%, na proporção de 2:1 (volume da salmoura/peso), por 30 minutos. Após foram lavados em água corrente e drenados por uma hora. Aos troncos e filés que receberam alecrim foi adicionado $0,5 \mathrm{~g}$ da planta (ramos e folhas) por filé e 1,0 g por tronco. Posteriormente, as amostras (troncos e filés) foram colocadas dentro da câmara de defumação para secagem parcial (aquecimento a gás) à uma temperatura de $40-50^{\circ} \mathrm{C}$, por 60 minutos. A temperatura inicial do processo de defumação foi de $50^{\circ} \mathrm{C}$ com razão de temperatura/tempo de $10^{\circ} \mathrm{C} /$ hora até $90^{\circ} \mathrm{C}$ (total de 4 horas de defumação). Os troncos após a defumação foram submetidos à filetagem e pesados novamente e as amostras para análise sensorial foram estocadas sob refrigeração $\left(5^{\circ} \mathrm{C}\right)$.

A defumação foi realizada na Estação Experimental de Piscicultura da UEM/CODAPAR, em defumador artesanal com geração de fumaça fora da câmara de defumação. O combustível para produzir a fumaça foi serragem de eucalipto rosa (Eucalyptus globulus Labill.) e utilizou-se gás de cozinha para manutenção da temperatura.

\section{Umidade e Lipídios totais}

Os filés in natura e os defumados foram embalados em sacos plásticos, identificados e congelados a $-18^{\circ} \mathrm{C}$ para posteriores análises. Foi realizada análise de umidade e lipídios totais em 5 filés defumados/tratamento e em 5 filés in natura sem pele (testemunha). A determinação de umidade foi realizada segundo normas da AOAC (CUNNIFF, 1998) e os lipídios totais foram determinados segundo o método de Bligh \& Dyer (1959).

\section{Rendimento e perdas durante o processamento}

Para determinação do rendimento dos filés processados, foram utilizadas 40 unidades/tratamento, sendo que o peso foi multiplicado por dois $\left(\mathrm{n}^{\mathrm{o}}\right.$ de filé por peixe). Todos os dados de rendimento foram calculados em relação ao peso total do exemplar [(Peso do filé defumado/peso peixe inteiro) x 100]. 


\section{Análise sensorial}

Amostras de tilápias defumadas $( \pm 5 \mathrm{~g})$ foram avaliadas por um painel de 40 provadores não treinados, cerca de 24 horas após a defumação. As amostras foram padronizadas em relação à posição de retirada do filé de forma a obter duas amostras por filé defumado. Estas amostras foram embaladas em papel alumínio e oferecidas aos provadores.

Os provadores receberam de maneira aleatória as amostras em pratos codificados com números (aleatórios) e uma ficha resposta. Foram avaliados os atributos de sabor, aroma, cor, textura, teor de sal e aceitação geral das porções dos peixes. Os produtos finais (filé inteiro com e sem alecrim) também foram avaliados quanto à aparência, cor, aroma e aceitação geral. Para tanto, foi utilizada uma ficha com escala hedônica de nove pontos com os extremos 1 (desgostei muitíssimo) e nove (gostei muitíssimo) (DUTCOSKY, 1996). Os dados dos resultados das características organolépticas dos filés defumados foram transformados de acordo com a fórmula : $\sqrt{(\mathrm{x}+0,5)}$.

\section{Delineamento experimental}

Para análise do rendimento, perdas durante o processamento e peso do produto final (filé), o delineamento experimental foi inteiramente casualizado num fatorial 2 × 2 constituído de duas formas de processamento $(\mathrm{T} 1=$ tronco limpo sem pele defumado e depois retirado o filé e $\mathrm{T} 2$ = filé sem pele defumado) e presença ou não de alecrim no tronco limpo e filé (A1 $=$ com alecrim e $\mathrm{A} 2=$ sem alecrim), com 40 repetições por tratamento. O filé foi considerado a unidade experimental.

Para análise sensorial foram utilizados 40 repetições, no delineamento em blocos casualizados, e cada provador foi considerado um bloco.

Os resultados foram submetidos à análise de variância, e as médias comparadas pelo teste de Tukey, ao nível de 5\% de significância, utilizando o programa de Análise Estatística ESTAT, desenvolvido pelo Departamento de Ciências Exatas da UNESP - Jaboticabal (BANZATTO \& KRONKA, 1995).

\section{RESULTADOS E DISCUSSÃO}

\section{Rendimento e perdas durante o processamento}

Os filés in natura utilizados para a defumação, apresentaram peso médio de 392,22 g e os troncos limpos de 555,28 g, respectivamente. Não houve diferença $(\mathrm{P}>0,05)$ entre os pesos dos filés e dos troncos que foram submetidos ao processo de defumação sem e com alecrim, mostrando que as amostras utilizadas para cada tratamento eram homogêneas. Os pesos médios dos filés submetidos à defumação com e sem alecrim foram 396,20 g e 388,23 g, respectivamente. Os troncos apresentaram os pesos médios de 540,86 g e 569,69 g para os processados com e sem alecrim, respectivamente (Tabela 1).

TABELA 1 - Médias dos pesos, rendimento dos filés defumados e perdas totais ocorridas durante o processamento dos filés de tilápia do Nilo (Oreochromis niloticus).

\begin{tabular}{lccc}
\hline Fatores de variação & $\begin{array}{c}\text { Peso dos filés } \\
\text { defumados }(\mathbf{g})\end{array}$ & $\begin{array}{c}\text { Rendimento dos } \\
\text { filés defumados }(\%)\end{array}$ & Perdas totais (\%) \\
\hline Forma de processamento (FPR) & 122,76 & 23,20 & 76,61 \\
Filé (FIL) & 181,77 & 35,64 & 64,13 \\
Filé do tronco defumado (FTD) & & & 73,57 \\
\hline Presença de Alecrim (PAL) & 135,04 & 26,49 & 67,17 \\
Com (PAC) & 169,50 & 32,34 & $628,368^{* *}$ \\
Sem (PAS) & & & $165,428^{* *}$ \\
\hline Teste F & $127,468^{* *}$ & $654,43^{* *}$ & $6,197^{*}$ \\
Forma de Processamento (FPR) & $43,480^{* *}$ & $144,78^{* *}$ & 4,47 \\
Presença de Alecrim (PAL) & $3,833^{*}$ & $4,932^{*}$ & 10,45 \\
Interação (TPR x PAL) & 21,70 & & \\
\hline C.V. (\%) & & & \\
\hline
\end{tabular}

\footnotetext{
*** significativo $(\mathrm{P}<0,01){ }^{*}$ significativo $(\mathrm{P}<0,05)$.
} 
No rendimento de abate e/ou filetagem, não houve diferença $(\mathrm{P}>0,05)$ para os troncos que seriam defumados com $(54,52 \%)$ ou sem $(53,41 \%)$ alecrim, e o mesmo foi observado nos filés com $(38,59 \%)$ ou sem $(37,71 \%)$ alecrim.

Os filés defumados, independentes da forma de processamento aplicada, apresentaram menor peso quando utilizado o alecrim. Os filés defumados com alecrim apresentaram peso inferior $(110,66 \mathrm{~g})$ aos filés sem alecrim $(134,89 \mathrm{~g})$. O mesmo ocorrendo para os filés obtidos a partir dos troncos com $(159,43 \mathrm{~g})$ e sem $(204,11 \mathrm{~g})$ alecrim (Figura 1).

Na Tabela 1 encontram-se os pesos, rendimentos e perdas dos filés defumados e dos filés obtidos a partir dos troncos defumados.

Houve efeito $(\mathrm{P}<0,05)$ da forma de processamento e presença ou não do alecrim no rendimento dos filés defumados de tilápia do Nilo. Observa-se que houve interação entre os dois fatores e o desdobramento dessas interações constam na Figura 1A e 1B.

Com o desdobramento da Forma de processamento $\mathrm{X}$ Presença ou não de alecrim, pode-se observar que a técnica de processamento na qual os filés foram retirados dos troncos defumados proporcionou maiores rendimentos $(32,17 \%$ e $39,10 \%)$ comparados à técnica em que foram defumados os filés $(20,81 \%$ e $25,58 \%)$ independentemente de terem sido defumados com ou sem alecrim, respectivamente.
Para a presença ou não de alecrim na defumação, os filés defumados e os filés dos troncos defumados com alecrim apresentaram menores valores de rendimentos $(20,81 \%$ e $32,17 \%)$ comparados aos defumados sem alecrim $(25,58 \%$ e $39,10 \%)$.

Houve diferença $(\mathrm{P}<0,05)$ entre as perdas ocorridas durante a defumação para presença ou não de alecrim. Os troncos defumados com alecrim perderam $7,2 \%$ de peso, enquanto os troncos defumados sem alecrim perderam $4,16 \%$ de peso em relação ao peso bruto do peixe. Os filés defumados com alecrim também diferiram dos filés defumados sem alecrim, e as perdas foram de $17,76 \%$ e $13,32 \%$, respectivamente, em relação ao peso total do peixe. Segundo Souza (2003), os rendimentos dos produtos defumados variam em relação à técnica de defumação, espécie de peixe, forma de apresentação do produto, entre outros.

As perdas durante a defumação nesse estudo com tilápia do Nilo concordam com Sigurgisladottir et al. (2000), que afirmam que podem variar de 10 a $25 \%$, dependendo do tipo de material in natura, característica do produto final e parâmetros usados no processo, tais como tempo e temperatura.

Os filés defumados perderam mais peso no processo de defumação em relação aos filés retirados a partir dos troncos defumados, concordando com Pereira \& Campos

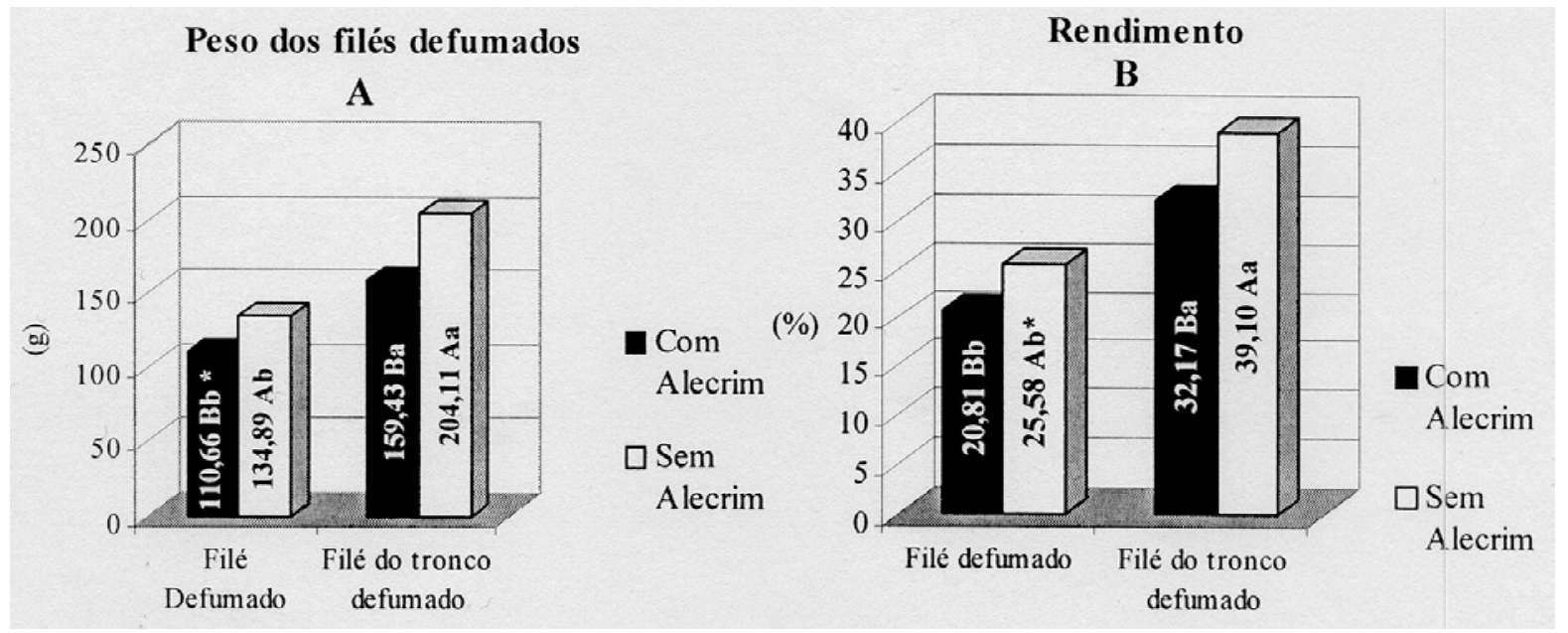

FIGURA 1 - Valores médios do desdobramento da interação entre Forma de processamento X Presença ou não de alecrim nos filés de tilápia do Nilo, para o peso (A) e rendimento (B).

${ }^{(*)}$ Médias seguidas de mesma letra minúscula para o fator de técnica de processamento dentro da presença ou não de alecrim e maiúscula para presença ou não de alecrim dentro da técnica de processamento não diferem pelo Teste de Tukey $(\mathrm{P}>0,05)$. 
(1998), que indicaram que o tipo de corte realizado no peixe influencia no rendimento ao submetê-lo à defumação. Esses autores encontraram valores de rendimento de defumação para o pacu (Piaractus mesopotamicus) em postas de $39,30 \%$ e em mariposa ou borboleta (filés retirados juntos, iniciando-se pela região dorsal, de forma que as duas faces do peixe fiquem unidas pela região ventral) de $38,60 \%$.

$\mathrm{O}$ fato das maiores perdas terem ocorrido nos filés durante o processo de defumação é explicado devido à desidratação que ocorre em maior grau na superfície do filé, uma vez que a relação superfície-volume deste, é maior comparado ao tronco, favorecendo a perda de água. Dessa forma, os filés defumados possuem maior relação superfície-volume comparada aos troncos defumados, ocorrendo maior desidratação e conseqüentemente maior perda e menores rendimentos.

\section{Análise Sensorial}

Os resultados das características organolépticas dos filés defumados e dos filés a partir dos troncos defumados sem e com alecrim, constam na Tabela 2 e 3.

Em relação ao produto final, quando analisado a técnica de processamento, os provadores, consideraram melhores características para os FIL $(2,88)$ em relação ao FTD $(2,63)$. Todavia, a presença do alecrim nos filés independente da forma de obtenção desse produto final, não foi significativo para aparência, cor, aroma e aceitação geral, e as notas transformadas variaram de 2,70 a 2,77, conforme a Tabela 2 .
Em relação às análises organolépticas das porções do defumado, os filés (FIL) apresentaram maiores valores médios nas notas para sabor, aroma, cor, textura e teor de sal comparado aos filés obtidos a partir dos troncos defumados (FTD). Mostrando que a preferência foi maior para o consumo dos FIL em relação aos FTD. Os provadores não notaram diferenças $(\mathrm{P}>0,05)$ quanto ao acréscimo de alecrim aos filés e filés a partir dos troncos defumados, exceto para teor de sal (Tabela 3 ).

De acordo com Beraquet \& Mori (1984), quando a temperatura é elevada (acima de $35^{\circ} \mathrm{C}$ ) a gordura do músculo aflora melhorando a aparência, brilho e proporcionando a retenção das substâncias aromáticas no filé e, conseqüentemente apresentando melhor aroma, cor e sabor. Segundo Oetterer (1995), as gotículas de gorduras ajudam na retenção dos componentes aromáticos da fumaça, conferindo sabor e odor agradáveis ao produto, assim à gordura do pescado atua como absorvedor das substâncias aromáticas presentes na fumaça. Isso pode explicar a melhor aceitação do produto final (aparência, cor e aroma) dos filés defumados, pois estes apresentaram teores médios de umidade de 60,87\%, os quais são menores $(\mathrm{P}<0,01) \mathrm{em}$ relação aos filés obtidos após defumação troncos $(67,35 \%)$, com conseqüente concentração de gordura, $6,75 \%$ e $5,51 \%$, respectivamente $(\mathrm{P}<0,01)$. Desta forma, melhorando a aparência e cor dos filés, e evidenciando as substâncias aromáticas absorvidas da fumaça pelas gorduras.

TABELA 2 - Médias das notas atribuídas às características organolépticas do produto final (filés) de tilápia do Nilo.

\begin{tabular}{|c|c|c|c|c|}
\hline \multirow[b]{2}{*}{ Fatores de variação } & \multicolumn{4}{|c|}{ Produto Final $^{(1)}$} \\
\hline & Aparência & Cor & Aroma & $\begin{array}{c}\text { Aceitação } \\
\text { Geral }\end{array}$ \\
\hline \multicolumn{5}{|l|}{ Forma de processamento (FPR) } \\
\hline Filé (FIL) & $2,88^{\mathrm{a}}$ & $2,91^{\mathrm{a}}$ & $2,81^{\mathrm{a}}$ & $2,88^{\mathrm{a}}$ \\
\hline Filé do tronco defumado (FTD) & $2,55^{\mathrm{b}}$ & $2,55^{\mathrm{b}}$ & $2,68^{b}$ & $2,63^{\mathrm{b}}$ \\
\hline \multicolumn{5}{|l|}{ Presença de Alecrim (PAL) } \\
\hline Com (PAC) & $2,72^{\mathrm{a}}$ & $2,73^{\mathrm{a}}$ & $2,77^{\mathrm{a}}$ & $2,77^{\mathrm{a}}$ \\
\hline Sem (PAS) & $2,70^{\mathrm{a}}$ & $2,73^{\mathrm{a}}$ & $2,72^{\mathrm{a}}$ & $2,75^{\mathrm{a}}$ \\
\hline \multicolumn{5}{|l|}{ Teste F } \\
\hline Forma de Processamento (FPR) & $62,276^{* *}$ & $106,942^{* *}$ & $10,790^{* *}$ & $76,203^{* *}$ \\
\hline Presença de Alecrim (PAL) & $0,257^{\mathrm{ns}}$ & $0,037^{\mathrm{ns}}$ & $1,817^{\mathrm{ns}}$ & $0,467^{\mathrm{ns}}$ \\
\hline Interação (TPR x PAL) & $0,602^{\mathrm{ns}}$ & $1,063^{\mathrm{ns}}$ & $0,853^{\mathrm{ns}}$ & $0,286^{\mathrm{ns}}$ \\
\hline C.V. $(\%)$ & 9,715 & 8,165 & 8,909 & 6,663 \\
\hline
\end{tabular}

(1) Para cada fator, médias seguidas de letra iguais não diferem significativamente pelo Teste de Tukey $(\mathrm{P}>0,05)$. * significativo $(\mathrm{P}<0,01){ }^{\mathrm{ns}}-$ não-significativo $(\mathrm{P}>0,05)$. 
TABELA 3 - Médias das notas atribuídas às características organolépticas para as porções dos filés defumados de tilápia do Nilo.

\begin{tabular}{|c|c|c|c|c|c|c|}
\hline \multirow[b]{2}{*}{ Fatores de variação } & \multicolumn{6}{|c|}{ Análise da porção do filé } \\
\hline & Sabor & Aroma & Cor & Textura & $\begin{array}{c}\text { Teor de } \\
\text { sal }\end{array}$ & $\begin{array}{c}\text { Aceitação } \\
\text { Geral }\end{array}$ \\
\hline \multicolumn{7}{|l|}{$\begin{array}{l}\text { Forma de processamento } \\
\text { (FPR) }\end{array}$} \\
\hline Filé (FIL) & $2,86^{\mathrm{a}}$ & $2,81^{\mathrm{a}}$ & $2,84^{\mathrm{a}}$ & $2,85^{\mathrm{a}}$ & $2,74^{\mathrm{a}}$ & $2,82^{\mathrm{a}}$ \\
\hline $\begin{array}{l}\text { Filé do tronco defumado } \\
\text { (FTD) }\end{array}$ & $2,69^{b}$ & $2,63^{b}$ & $2,54^{b}$ & $2,72^{b}$ & $2,63^{b}$ & $2,66^{b}$ \\
\hline \multicolumn{7}{|l|}{ Presença de Alecrim (PA) } \\
\hline Com (PAC) & $2,80^{\mathrm{a}}$ & $2,72^{\mathrm{a}}$ & $2,72^{\mathrm{a}}$ & $2,80^{\mathrm{a}}$ & $2,74^{\mathrm{a}}$ & $2,76^{\mathrm{a}}$ \\
\hline Sem (PAS) & $2,75^{\mathrm{a}}$ & $2,72^{\mathrm{a}}$ & $2,66^{\mathrm{a}}$ & $2,77^{\mathrm{a}}$ & $2,62^{\mathrm{b}}$ & $2,72^{\mathrm{a}}$ \\
\hline \multicolumn{7}{|l|}{ Teste F } \\
\hline $\begin{array}{l}\text { Forma de Processamento } \\
\text { (FPR) }\end{array}$ & $19,917^{* *}$ & $17,716^{* *}$ & $36,168^{* *}$ & $12,866^{* *}$ & $4,278^{*}$ & $14,398^{* *}$ \\
\hline Presença de Alecrim (PAL) & $1,540^{\mathrm{ns}}$ & $0,002^{\mathrm{ns}}$ & $1,252^{\mathrm{ns}}$ & $0,486^{\mathrm{ns}}$ & $5,555^{*}$ & $0,847^{\mathrm{ns}}$ \\
\hline Interação (TPR x PAL) & $0,292^{\mathrm{ns}}$ & $0,601^{\mathrm{ns}}$ & $0,286^{\mathrm{ns}}$ & $0,108^{\mathrm{ns}}$ & $0,708^{\mathrm{ns}}$ & $0,285^{\mathrm{ns}}$ \\
\hline C.V. $(\%)$ & 8,69 & 9,63 & 12,02 & 8.74 & 12,57 & 9,72 \\
\hline
\end{tabular}

Mesmo sendo um peixe considerado magro pelo baixo teor de lipídios apenas 5,57\% no filé in natura, não sendo este indicado para defumação, os filés defumados tiveram boa aceitação pelos provadores devido às características organolépticas analisadas.

O valor médio transformado $(2,88)$ para filé defumado quanto à aparência do filé de tilápia defumado $\left(50^{\circ} \mathrm{C}\right.$ a $90^{\circ} \mathrm{C}$ por 4 horas) neste experimento, foram superiores aos encontrados por Souza et al. (2000, 2004). Em relação aos outros atributos relacionados ao produto final, os valores encontrados nesse experimento foram superiores aos encontrados por Souza et al. (2004), já em relação à porção os valores foram semelhantes.

A apresentação do pescado de forma mais elaborada, como no caso dos defumados, associada ao uso de antioxidantes naturais, como algumas especiarias, além de aumentar a vida útil desse produto o torna mais apreciado pelo consumidores, estimulando seu consumo.

\section{CONCLUSÕES}

A forma de processamento em filé é mais indicada para a defumação de tilápia do Nilo (Oreochromis niloticus), apesar de ter apresentado menor rendimento no processo. Na forma de filé apresentou maior aceitação pelos provadores quanto às características organolépticas. Como não houve influência do alecrim nos filés defumados é indiferente à aplicação deste na quantidade e forma mencionada.

\section{AGRADECIMENTOS}

À CAPES, pelo auxílio e bolsas de pós-graduação concedidas.

À Secretaria Especial de Aqüicultura e Pesca da Presidência da República (SEAP/PR).

\section{REFERÊNCIAS BIBLIOGRÁFICAS}

BANZATTO, D. A.; KRONKA, S. N. Experimentação agrícola. 3. ed. Jaboticabal: FUNEP, 1995. 247 p.

BERAQUET, N. J.; MORI, E. R. M. Influência de diferentes métodos de defumação na aceitabilidade de cavalinha (Scomber japonicus Hout) defumada. Coletânea do ITAL, Campinas, v. 14, p. 1-25, 1984.

BLIGH, E. G.; DYER, W. J. A rapid method of total lipid extraction and purification. Canadian Journal of Biochemistry and Physiology, Ontario, v. 37, n. 8, p. 911917, 1959. 
COUNCIL OF EUROPE. Flavouring substances and natural sources of flavourings. 3. ed. Strasbourg: Maisonneuve, 1981.

CUNNIFF, P. A. (Ed.). Official methods of analysis of AOAC Internacional. 16. ed. Arlington: AOAC, 1998. CD-ROM.

DUTCOSKY, S. D. Análise sensorial de alimentos. Curitiba: Champagnat, 1996. 123 p.

JORY, D. E.; ALCESTE, C.; CABRERA, T. R. Mercado y comercialización de tilapia en los Estados Unidos de Norte América. Panorama Acuicola, Sonora, v. 5, n. 5, p. 50-53, 2000.

MADSEN, H. L.; NIELSEN, B. R.; BERTELSEN, G.; SKIBSTED, L. H. Screnning of antioxidants between assays based on ESR spin trapping and electrochemical measurement of oxygen consumption. Food Chemistry, New York, v. 57, n. 2, p. 331-337, 1996.

OETTERER, M. Pescado defumado: unidades processadoras e operação de defumadores artesanais. In: SEMINÁRIO SOBRE TECNOLOGIA DE SALGA E DEFUMAÇÃO DE PESCADO, 1995, Campinas. Anais... Campinas: Unicamp, 1995. p. 18-32.

PEREIRA, K. C.; CAMPOS, A. F. M. Estudo do rendimento de filetagem de bagre africano Clarias gariepinus e bagre americano (Ictalurus punctatus). In: REUNIÃO ESPECIAL DA SOCIEDADE BRASILEIRA PARA O PROGRESSO DA CIÊNCIA, 6., 1998, Maringá. Anais... Maringá: Sociedade Brasileira para o Progresso da Ciência, 1998. p. 523-524.
SHAHIDI, F.; WANASUNDARA, P. K. J. P. D. Phenolic antioxidants. Critical Reviews in Food Science and Nutrition, Amherst, v. 32, n. 1, p. 67-103, 1992.

SIGURGISLADOTTIR, S.; SIGURGISLADOTTIR, M. S.; TORRISSEN, O. Effects of different salting and smoking processes on the microstructure, the texture and yield of Atlantic salmon (Salmo salar) fillets. Food Research Internacional, Ontario, v. 33, p. 847-855, 2000.

SOUZA, M. L. R. Processamento do filé e da pele da tilápia do Nilo (Oreochromis niloticus): aspectos tecnológicos, composição centesimal, rendimento, vida útil do filé defumado e teste de resistência da pele curtida. 2003. $169 \mathrm{f}$. Tese (Doutorado em Zootecnia) - Universidade Estadual Paulista, Jaboticabal, 2003.

SOUZA, M. L. R.; BACCARIN, A. E.; MACEDOVIEGAS, E. M.; KRONKA, S. N. Defumação da tilápia do Nilo (Oreochromis niloticus) inteira eviscerada e filé: aspectos referentes às características organolépticas, composição centesimal e perdas ocorridas no processamento. Revista Brasileira de Zootecnia, Viçosa, v. 33, p. 27-36, 2004.

SOUZA, M. L. R.; MACEDO-VIEGAS, E. M.; CARNEIRO, D. J. Comparação dos processos de defumação a frio e a quente de matrinxã (Brycon cephalus) sobre o rendimento e características organolépticas. In: AQUICULTURA BRASIL, 11., 2000, Florianópolis. Anais... Florianópolis: Simbraq, [2000]. CD-ROM. 